\title{
Advanced Driver Assistance Systems and Animals
}

\author{
Oliver Bendel
}

Received: 25 April 2014/ Accepted: 22 September 2014/Published online: 9 October 2014

(C) Springer-Verlag Berlin Heidelberg 2014

\begin{abstract}
Advanced driver assistance systems are widely used. Some support and inform the driver. Others relieve him or her of certain tasks-and transform the humanguided system into a semi-autonomous one. For some years also fully autonomous systems have been on the roads, socalled self-driving cars, as prototypes of companies and within research projects. From the perspective of ethicsboth of the special fields of ethics like animal ethics, information ethics and technology ethics and of machine ethics which can be understood as a counterpart to human ethics-advanced driver assistance systems raise various questions. The aim of this paper is to derive suggestions from animal ethics and other disciplines for the improvement and development of the systems. The basis are literature analysis and own classifications and considerations. The result is that there are many possibilities to expand existing systems and to develop new functions in the context with the aim to reduce the number of animal victims.
\end{abstract}

Keywords Advanced driver assistance systems $\cdot$ Selfdriving cars · Road kill · Animal ethics - Information ethics $\cdot$ Technology ethics $\cdot$ Machine ethics

O. Bendel $(\square)$

School of Business, Institute for Information Systems, University of Applied Sciences and Arts Northwestern Switzerland FHNW, Bahnhofstrasse 6, 5210 Windisch, Switzerland

e-mail: oliver.bendel@fhnw.ch

URL: http://www.fhnw.ch/personen/oliver-bendel

\section{Introduction}

Passenger cars and other motor vehicles are more and more resembling rolling computers or mobile robots that partly, and at some time in the future might even fully, decide and act autonomously, as kinds of independent subjects, without human intervention in a given period of time [9]. The value of on-board electronics (car IT) is increasing continuously, while some components are getting cheaper at the same time. ${ }^{1}$ Advanced driver assistance systems (ADAS) like anti-lock braking systems (ABS) and electronic stability programs (ESP) have become standards, and now that many cars have automatic light enhancing, automatic windshield wiper systems and electronic parking brakes, assisted cruise control, brake assist, emergency brake assist and lane change assist are growing more important. Assistance systems are also installed in farming vehicles, where the focus is more on efficiency and operative safety (and less on safe driving) [23].

Every year, more than one million people are killed on the roads [27], and millions are injured. Not only the victims suffer (if they have the time to do so), their partners and families suffer too [5]. Death is virtually on board, and it is hard to understand why the use of mobility is weighed so much higher than the damage caused by it. Of course we witness many efforts for reducing the number of casualties, but while driving is becoming safer, traffic is ever growing [19], in countries like China and worldwide. The efforts concentrate less on animals as the weakest players in traffic, exposed to heavy traffic on the roads. Every year, billions of higher-developed animals are killed on the road [29]. In the USA alone, the estimated number of road kills

\footnotetext{
${ }^{1}$ The term "car IT" means not only ADAS, but also navigation systems and dashboard cameras (dashcams) [18].
} 
is one million per day [35]. Further to birds, frogs, hedgehogs, squirrels, hare, foxes, wild boards and deer, pets are also affected, first of all dogs and cats which are killed in towns and villages (or that are even passengers in cars).

The driver-supporting assistance systems would be suited to help animals too. Nobody wants to roll over a hedgehog, and a collision with deer can impact the car and the driver seriously. In all, further development of advanced driver assistance systems might be justified with moral, technical, economical and safety-related reasons. This article analyses how assistance systems (and selfdriving cars) selected from the perspective of animal ethics might contribute to the well-being of animals [6]. Information, technology and machine ethics are considered on the side. The objective is to derive proposals for improving and optimizing traffic and road safety devices as the wellbeing of animals should be compatible to the well-being of humans who want to be and remain mobile. The analysis focuses on passenger cars and road traffic. Suggestions for agricultural use are given as a by-thought.

\section{Overview of Advanced Driver Assistance Systems}

Modern cars cannot be imagined without advanced driver assistance systems. These systems support drivers of motor vehicles and in certain situations they take over drivers' tasks [3]. Most of them are computer systems connected to input and output devices, with access to several components and functions of vehicles. Technologies are usually integrated by permanently installed hardware with embedded software. Some concepts however outsource or mobilize the display and sensors-Google Glass [24] is one example. The purpose of application is making driving safer, more comfortable, and more efficient (for instance by cutting back the energy consumption). The design of many systems enables the driver to override the system temporarily and allow or necessitate manual control or individual commands. This is owed to reasons of liability and safety technology. Some systems substitute earlier functions, others offer new ones.

Some examples of ADAS are the anti-lock braking system, electronic stability program, automatic light enhancing, automatic windshield wiping, traffic sign recognition, electronic parking brake, brake assist, emergency brake assist, lane change assist, lane change support, intelligent speed adaption, assisted cruise control, anticollision control, drowsy driver alert system, tire pressure control system and parking assist [31]. This article focuses on assistance systems that intervene in the starting, steering, controlling and braking of motor vehicles, and prioritize on safe driving. They are specified briefly as follows:
- The brake assist in its simple version is a brake booster that enhances the pedal pressure when the driver brakes and manoeuvres. This means it is activated based on an action of the driver interpreted by the system.

- An emergency brake assist recognizes a dangerous traffic situation via suitable sensors, and triggers emergency braking. It performs automatic manoeuvres, which means the system recognizes a dangerous situation, especially in front of the car, and then decides and acts accordingly.

- The lane change assist warns the driver with light or sound signals or vibration when changing a lane would lead to a collision. The system realizes there is a risk, especially along the sides of a car, and brings it to the attention of the driver to make him or her react accordingly.

- The lane change support automatically returns the car to the original lane in case of an imminent side collision. This means it recognizes a risk situation by sensors and then decides and acts accordingly.

- With traffic sign recognition, the traffic signs on the lane the car drives on are identified by means of a camera and image recognition, and then they are shown and explained on a display. The system is of informative character, but it can be connected to intelligent speed adaption or emergency brake assist which decelerate or brake the vehicle.

Not all types of ADAS are clearly distinguished from each other, some are related to others. Some can be described as a combination. The congestion assistant is an example of the combination of assisted cruise control and brake assist or emergency brake assist. Some ADAS are continuously improved, or redesigned to produce new types. The terminology is not standardized. Informing and enhancing as well as automatic systems are in use for safe driving.

Assistance systems use different sensor systems [31]: ultrasonic sensors (for the parking assist), radar (for the lane change assist, assisted cruise control, anti-collision assist), lidar (for the lane change assist, lane change support, assisted cruise control, anti-collision assist), infrared laser (for night vision enhancing, frequently in conjunction with an emergency brake assist) as well as mono and stereo cameras (emergency brake assist, lane change assist, lane change support, traffic sign recognition). As already mentioned, the sensors can also be accommodated in separate devices, and Google Glass and Samsung Galaxy Smart Glasses or smartwatches may be examples. Partly they cooperate with and supplement each other. Mostly they depend on other functions, for instance on image and pattern recognition and other results of computer science and artificial intelligence (AI). Surround sensors are 
relevant for robots as well. Robots need them to detect and overcome obstacles, and for general orientation. A different automation technology is found in the combination of computer systems and signals provided from the surroundings (RFID, GPS, motion sensors, light signals).

The integration of systems and sensors is elementary for successful operation of self-driving cars. In colloquial language they are called robot cars. They take over certain, or even all, activities of the driver (or passenger) in road traffic. They are designed to unburden or replace drivers, optimize traffic flow, and minimize the risk of accidents [19]. Some prototypes are well-known, such as the Google Driverless Car or the outcomes of projects like the Safe Road Trains for the Environment (SARTRE) funded by the EU [15]. Self-driving cars are already seen on the roads of some European cities [30]. Inside, the human is monitoring the system, as a driving instructor would monitor a learner [22]. Traffic dominated by self-driving cars is a vision, a vision however that fuels and drives the development of novelty driver assistance systems. By 2035, more than ten million such systems will be sold, and more than 50 million should be in use all over the world [21].

\section{Ethics and Specific Fields of Applied Ethics}

Ethics is an old discipline of philosophy. Morality and the will for moral behavior are its objects [28]. It can be pursued as theoretical or as applied ethics. The latter establishes specific fields of ethics relating to segregated applications. Examples are environmental, bio, animal, military, technology, information, media, business, political and legal ethics. In a way, information ethics is in the centre of the fields of applied ethics [13]. These have to communicate with information ethics considering how information and communication technologies (ICT) and computer systems are integral parts of their fields of application.

The object of information ethics is morality of and in the information society. It analyses how, when offering or using ICT as well as new media, we behave or should behave in terms of morality [13]. It includes computer, network and new media ethics. Technology ethics relates to ethical issues of the use of technology. The technology can be the one of houses, vehicles or arms. The object of machine ethics is the (specifically understood) morality of semi-autonomous and autonomous programs and systems (which function temporarily or in the long-term independent of humans), as in agents, chat bots, robots, unmanned aerial vehicles or self-driving cars [12]. It can be classified as a part of information and technology ethics or it can be understood as an equivalent to human ethics and as an independent major discipline [11]. Machine ethics is a young field in which AI experts, robotics and computer scientists as well as philosophers are engaged [1]; robot ethics is a germ cell and a special field of and besides it [2]. ${ }^{2}$ Surely machine morality and human morality are very different, and the appropriateness of the terms is intensively discussed [1].

There is more or less agreement that machines, be they unmanned aerial vehicles or motor vehicles [33], have to be capable of making decisions with ethical implications without human support. Different from animals, they can judge several alternatives with a rational and future-oriented approach, and in the best case they can make the best choice, (also in ethical terms) based on facts (like capacity for suffering, medical condition, age, to speak within the animal-related context), following suitable rules and models of normative ethics and comparing cases or using observations. These are not free decisions, but under certain circumstances they are more open and more unpredictable from the outside than decisions by animals. ${ }^{3}$

Animal ethics (which can be seen as a part of environmental or bio ethics) deals with the duties humans have towards animals as objects of morality and with the rights of animals [34]. Duties of animals do not exist in terms of morality, considering they are not subjects of morality and do not make free decisions based on rational thinking; rather they are determined by dispositions, instincts and reflexes. The capacity of suffering is an important moral and ethical criterion. It can justify the requirement of adjusting husbandry to the needs of the species, or introducing a ban on the keeping and use of animals. Altering a famous statement by Jeremy Bentham we could not only ask whether animals might suffer, we could also ask whether they have the will to live. ${ }^{4}$ Under certain circumstances, this will might justify a ban on killing them. Regardless of such justifications, most people do not want to collide with animals, rather they want to spare them suffering and save trouble and costs for themselves. The Western culture maintains a widely accepted consensus on

\footnotetext{
2 A central publication in this field is "Machine Ethics" by Michael and Susan Leigh Anderson as editors [1]. Important is also "Moral Machines" by Wallach and Allen [33]. With respect to "Machine Ethics", it can be said in summation that some authors refer critically to Isaac Asimov and his famous Three Laws of Robotics and reflect upon the basic meanings and implications of machine ethics. Some authors discuss deontological or teleological normative models with respect to the use for machine morality. James Gips focusses on virtue ethics. Bruce M. McLaren promotes a case-based reasoning, and Marcello Guarini gives a neural network approach.

${ }^{3}$ We are not going to discuss problematic terms and concepts of machine ethics in depth. In its brief existence, this young discipline has produced many articles and books related to these issues. As examples we mention [1] as well as [33].

4 Bentham wrote in "An Introduction to the Principles of Morals and Legislation": "The question is not, Can they reason? nor Can they talk? but, Can they suffer?" [14].
} 
avoiding unnecessary suffering or unreasonable killing of animals. However, most people are not aware of the smallest beings such as insects. With large species, such as wild boar or moose, one's own safety is the priority. This article is not intended to explain how this consensus does not exclude the occurrence of several inconsistencies and paradoxes. Examples can be found in husbandry or pet keeping or the consumption of meat.

Animals are furnished with RFID tags (RFID is the acronym of "radio-frequency identification"), traced by tracking devices, and managed by machines, therefore information ethics (and partly also technology ethics) addresses the rights and duties of creatures in the information and knowledge society, with the opportunities of designing information technologies and application systems to adjust to species and animals. Machine ethics inquires how to optimize (semi-)autonomous systems interacting with animals (animal-machine interaction in case of higher animals [8]) in ethical terms. According to the actor-network theory, the systems can be described as "actants" [4], as acting subjects which are not necessarily humans ("actors") or animals. Animal ethics today definitely has to cooperate with information ethics, technology ethics and machine ethics.

\section{Advanced Driver Assistance Systems in Relation to Animals}

As already mentioned, below we concentrate on advanced driver assistance systems in the narrower sense of the term, respectively on safe driving (safe also for animals) with the help of certain kinds of car IT. Considering the issues and topics of animal ethics, and based on the selected systems, we describe present and future options. In some cases we believe that it is necessary to take other special ethics and machine ethics into account. The underlying intention is to improve and develop ADAS by means of ethical considerations without going into technical details in this article.

In the present context, animal ethics focuses on the animal as the object of the morality of humans and machines, and it can clarify and represent the rights of animals in road traffic. The size of animals at risk is less relevant for animal ethics, while the capacity to suffer (which of course can be linked with the size), the age, health and frequency of occurrence of individuals as well as the level of development, and where applicable the degree of threat of extinction of the species are relevant. Species as such have no rights, and it is questionable whether they may be considered as an object of morality in the narrower sense of the term. However there should be no doubt that most animals depend on other members of their species, and usually living in a sufficiently large group (a herd or shoal) or an entire population will benefit their existential use and their social lives. The protection of species can be the object of animal ethics and of environmental ethics in a narrower sense. In the context of mobility, the central issues of animal ethics are the animal suffering, the (method of) animal killing, and the relationship between the individual and the species.

\subsection{Brake and Emergency Brake Assist}

The brake assist is relevant already today as it supports human actions and reactions relating to animals. Systems that could distinguish not only between humans and animals but also between animals and between species would be helpful [5]. ${ }^{5}$ They would be able to inform the driver about the individuals, the species, the background and circumstances. With regards to individuals, it is important to know if and how they might suffer, and whether they are healthy or sick animals. ${ }^{6}$ With regards to species it is important to know whether they are endangered or existential for others. When suggestions are submitted to the driver for decision-making, results of animal ethics and environmental ethics and of the research on the variety of species as well as biodiversity generally can be considered. Further development of sensors and of image and pattern recognition would be desirable. Sensor development also would have to include audio sensors. Cars should not only see but also hear animals, including frequencies inaudible for humans [6]. Radio chips could be an option, the type that can be integrated in the environment as well as the types already available, for instance RFID tags for farm animals. Electronic signals of animals lost and erring across the road could alert the car of the danger.

The emergency brake assist when combined with suitable technologies can help avoid hurting or killing animals [6]. Systems capable of recognizing and distinguishing humans and animals in the darkness with night vision enhancement are available on the market [17, 21]. A warning is transmitted to the driver, who then can slow down. The systems can be combined with the emergency braking system that actuates automatically when-as happens frequently when driving late in the evening-there is very little time for human reaction. Things are more

\footnotetext{
5 A team around Dah-Jye Lee has developed an algorithm suitable for distinguishing between species: "The team has also tested their algorithm on a dataset of fish images from BYU's biology department that included photos of four species: Yellowstone cutthroat, cottid, speckled dace and whitefish. The algorithm was able to distinguish between the species with $99.4 \%$ accuracy." [20].

${ }^{6} \mathrm{We}$ would like to emphasize here that these facts do not automatically lead to decisions. They can be a part of the chain of reasoning, and the needs and priorities of engineers, producers and customers must be weighed up against each other.
} 
complicated if another car tailgates closely. The central goal is not to create unnecessary risks for traffic participants by driving a car. It is obvious that there can be conflicts between human ethics and animal ethics. Again, systems able to distinguish not only between humans and animals, but also between animals (as individuals) and between species would be worth developing. Fully autonomous braking is also an issue of machine ethics. The machine has to make morally relevant decisions, as these decisions affect the well-being of the animal. In general, next to suitable rules and models of normative ethics [11] new developments in the field of sensors and image and pattern recognition would be desirable.

Large combine harvesters, which are of marginal interest here, move through very complex environments. They work on meadows or fields of corn and maize where visibility is limited. Deer fawns are prone to be caught in the cutters [23]. This is of importance because of the damage caused to the machinery and the lost times of harvesting and from the perspective of information and technology ethics (the human who feels guilty after having killed an animal with a machine) and animal ethics (an animal is killed with the machine without intention or probable gain). In this environment, the application of a standard emergency brake assist is very limited. There are solutions other than special audio systems that filter animal noise from the machine noise, for example GPS, thermal imaging cameras or unmanned aerial vehicles that fly ahead of the machines and communicate with them [22]. These concepts might benefit road traffic, where the surround analysis suddenly can get very difficult through fog or nightfall.

\subsection{Lane Change Assist and Lane Change Support}

Initially, the lane change assist seems not to be of any significance in this context. If it actuates after detecting an animal, the danger will be over. However, an extended assistance system can inform other cars or drivers, or the high-way patrol about an animal on the lane or the by-pass lane [5]. By principle, the brake assist can do the same, yet the lane change assist detects even animals that are not relevant for one's own car and that other systems might not detect and consider [6]. Suitable components and sensors could provide information on size, gender, status and type and target of the moving animal. Again, RFID of farm animals might be considered. Such an assistant would also be capable of analysing the behaviour of birds of prey hovering along the roadside as potential traffic casualties. In so far, several animals have to be considered in their relationship to each other.

This extended function might be used for combine harvesters driving along certain tracks. It could detect deer fawns, clutches of eggs or couples of ducklings without having to use unmanned aerial vehicles (which imply new problems and risks). In lush fields or high grass, it would have to be connected to additional technologies such as radar, thermal imaging camera, and audio system. Coupling it with scarecrow systems (which usually do not work with a roe deer fawn) could avoid losses of efficiency (caused by machine standstill). Alternatively, human assistants could be engaged for the secure remove of the animals.

The lane change support could be useful in interactions with animals. Imagine you were driving slowly because of the traffic flow or bad weather, and suddenly an animal approaches the vehicle from the rear or from the side. This might not be very probable in Central Europe, but it happens quite frequently in Scandinavia, Canada or certain southern countries. The car could by-pass the animal as a precaution, or drive away from it, taking care-and this is also an issue of machine ethics-not to scare or hurt it.

\subsection{Traffic sign recognition}

Integrating traffic sign recognition will be helpful in this context [7]. Today, it is possible to identify animal-related warning, cautioning and prohibiting signs, signs warning of the general presence of animals, of deer crossing, or of equestrian lanes [5]. From the perspective of animal or environmental ethics, both individuals and species are to be protected. Non-standardized elements such as signs pointing towards cattle drives or frog leaps could be considered [6]. The elements could be furnished with signals or transmitters so the system would not depend on image and pattern recognition only. When the vehicle approaches, these technologies inform it about the type of danger, if the danger currently exists, and how best to deal with it [6]. When the traffic sign recognition is combined with emergency brake assist the car will be able to brake autonomously when needed. Again, this is an issue of machine ethics. One has to "feed the system" with information on which animals the car should brake for or not, also with the necessity of not endangering passengers on board or other traffic participants. The general objective is to optimize advanced driver assistance systems further, also with regards to the recognition of surroundings, integrating socalled thinking things that will make it part of the Internet of Things [16].

Intelligent, interactive signs adjusting to the local circumstances might be another option. Again, information from the radio chips of farm animals (and pets) or from connected databases, information systems and the internet might be used for the purpose. The elements might not only alert the driver of the danger, but also propose the best conduct. Similar approaches are already used for speed 
limiting. Emoticons indicate whether or not the system is "satisfied" with the speed, or the situation is specified with terms like "attention" or "danger". Such signs could interact with advanced driver assistance systems. ${ }^{7}$

\section{Self-Driving Cars}

Self-driving cars are able to provide more sophisticated functions [32]. Based on the latest information, they can avoid problematic areas or times of the day autonomously, and-as illustrated above with the example of the combine harvester-rely on interaction with beings, warn or scare them away (not least an issue of animal-machine interaction [8]). The machine-machine communication, especially the communication between cars (car2car communication), and the communication between cars and the internet and information systems and between cars and radio chips in or on animals and other signal providers, are also very important [7]. Cars regulate their speed, intervals, and priorities interactively in correlation for best possible traffic flow. In future they might even share information with each other and with databases or networks to be able to make logistically [17] and ethically adequate decisions [11], or signals can influence them. The data flows make it a special matter of information ethics. The issue is to protect the informational autonomy of the driver [6]. Also the hacking and the "hostile bid" of the car constitute serious problems (e.g. for the security and the personal autonomy) which can be investigated by information and technology ethics [26]. As already mentioned above, cooperation between machines with different specific capacities by interaction between ground and air bound vehicles might be reasonable.

Self-driving cars require more complex concepts from machine ethics. An ethical machine should be able to respond adequately in relation to all beings provided this is within its powers, but recognition of small and smallest beings such as gastropods or insects is not in its powers. The relevant classic normative models, as for instance the ethics of duties or consequences have to be considered, and new models of normative ethics have to be developed [10]. Simply following pre-defined rules is not enough. Observations and case studies have to be considered, rules have to be prioritized and adjusted. When machines decide autonomously, matters of acceptance, safety and liability are highly relevant, which again affects information and technology ethics as

\footnotetext{
7 Such traffic signs are elements of the gamification of road traffic. This approach plays a part in many contexts, for example in learning and marketing. An interesting feature is that the smileys are signs used in computer-based communication and understood not only by humans, but by machines as well.
}

well as jurisprudence. In the end it could not only turn out that self-driving cars require very complex concepts, but that these complex concepts could be a source of risk for all participants.

\section{Conclusion and Outlook}

More and more advanced driver assistance systems are being installed that support or "alternate" with the driver in many different ways. In combinations they lead to selfdriving cars in which the driver is turned into a front-seat passenger. From the perspective of animal ethics and animal welfare, there is considerable need for improvement in the systems, especially with regards to "safety for all". Information and technology ethics can contribute to these questions. Solutions for avoiding casualties of animals or humans, and protecting the species, have to be researched. The desire for highest possible mobility is a reality and not going to lessen. It is important to consider the rights of all involved and affected.

Animal ethics should open up towards current technological options. Until today, this discipline hardly perceives developments of robotics beyond milking machines and picking systems (that can disturb and destroy animal life). Only in the USA there are a few basic approaches towards an animal-computer interaction that might lead to see the necessity of technology-focused animal ethics [25]. Animal ethicists also have to deal with economic perspectives, and make them fruitful for their work. One day, cars that protect animals might sell better than cars that treat animals like objects, or perceive them as obstacles only.

This article does not want to support the instrumentality or denial of ethics. The question is how the industry is going to respond to issues communicated by ethicists. Surely, drivers can be made wanting to be able to better protect animals. The industry will focus more on economic aspects. Drivers might assert pressure with their demand for new car models. This they surely will do once they get informed and conscientious of ethical and environmental issues, and when getting aware of functions that could avert damage from their passenger cars or farming machines. This brings us back to the economic perspective that cannot be by-passed. Perhaps it is possible to reconcile different points of view and conflicting interests with each other.

\section{References}

1. Anderson M, Anderson SL (eds) (2011) Machine ethics. Cambridge University Press, Cambridge

2. Asaro PM (2006) What should we want from a robot ethic? Int Rev Inf Ethics (Issue: Ethics in robotics) 6:10-16 
3. Becker J (2013) Ziemlich beste Freunde. Süddeutsche.de, 17.10.2013. http://www.sueddeutsche.de/auto/2.220/fahrer-assis tenzsysteme-in-autos-ziemlich-beste-freunde-1.1737337

4. Bendel O (2014) Wirtschaftliche und technische Implikationen der Maschinenethik. Die Betriebswirtschaft 4(2014):237-248

5. Bendel O (2014) Für wen bremst das Roboterauto? Computerworld.ch, 16.5.2014. http://www.computerworld.ch/marktanaly sen/studien-analysen/artikel/

6. Bendel O (2014) Fahrerassistenzsysteme aus ethischer Sicht. Zeitschrift für Verkehrssicherheit 2(2014):108-110

7. Bendel O (2014) Das Tier als Objekt der Moral der Maschine: Zum Verhältnis von Tier- und Maschinenethik. Telepolis, 2.1.2014. http://www.heise.de/tp/artikel/40/40684/

8. Bendel O (2013) Considerations about the relationship between animal and machine ethics. AI \& SOCIETY ("Online-First"Article on SpringerLink)

9. Bendel O (2013) Asimovs Automatobile: Selbstständig fahrende Autos in Fiktion und Realität und als Gegenstand der Maschinenethik. Telepolis, 27.8.2013. http://www.heise.de/tp/artikel/ 39/39728/1.html

10. Bendel O (2013) Towards a machine ethics. Technology assessment and policy areas of great transitions: book of abstracts. 1st PACITA Project Conference, March 13-15, 2013. Prague, Czech Republic, pp 229-230. http://pacita.strast.cz/en/ conference/documents

11. Bendel O (2012) Die Moral der Maschinen: Überlegungen zur Maschinenethik. inside-it.ch, 24.10.2012. http://www.inside-it. ch/articles/30517

12. Bendel O (2012) Maschinenethik. Gabler Wirtschaftslexikon. Gabler/Springer, Wiesbaden. http://wirtschaftslexikon.gabler.de/ Definition/maschinenethik.html

13. Bendel O (2012) Informationsethik. Gabler Wirtschaftslexikon. Gabler/Springer, Wiesbaden. http://wirtschaftslexikon.gabler.de/ Definition/informationsethik.html

14. Bentham $J$ (1828) An introduction to the principles of morals and legislation. A new edition, corrected by the author. B. Bensley, London, pp 235-236

15. Büttner R (2011) Projekt Sartre: Der Traum vom selbstständig fahrenden Auto. Spiegel Online, 20.1.2011. http://www.spiegel. de/auto/aktuell/projekt-sartre-der-traum-vom-selbststaendig-fah renden-auto-a-740501.html

16. Fleisch E, Mattern F (eds) (2005) Das Internet der Dinge: Ubiquitous Computing und RFID in der Praxis. Springer, Berlin, Heidelberg, New York

17. Gorhau S (2013) Große Entspannung, serienmäßig. Süddeutsche.de, 3.7.2013. http://www.sueddeutsche.de/auto/neue-sklasse-von-mercedes-barockschloss-und-raumschiff-1.1711435-2

18. Gorhau S (2013) Darum installieren viele Russen Kameras im Auto. Süddeutsche.de, 15.2.2013. http://www.sueddeutsche.de/ auto/verkehrsrecht-darum-installieren-viele-russen-im-autokameras-1.1601320

19. Grösch L (2013) Fehler Mensch. Automobilindustrie 3(2013):32-33

20. Hollingshead T (2014) BYU's smart object recognition algorithm doesn't need humans. News of Brigham Young University, 15.1.2014. http://news.byu.edu/archive14-jan-objectrecognition. aspx

21. IHS (2014) Emerging technologies: autonomous cars-not if, but when. Englewood

22. Kolhagen J (2013) Autopiloten auf Rädern. Versicherungswirtschaft, 1.6.2013 68(11):70

23. Kurz C, Rieger F (2013) Arbeitsfrei: Eine Entdeckungsreise zu den Maschinen, die uns ersetzen. Riemann Verlag, München

24. Lehmhofer E (2014) Harman: Die Zukunft des Fahrens mit Google Glass und seinem proprietären Fahrerassistenzsystem. m2mmagazin.de, 8.1.2014. http://m2m-magazin.de/harman-diezukunft-des-fahrens-mit-google-glass-und-seinem-proprietaerenfahrerassistenzsystem/

25. Mancini C (2011) Animal-computer interaction (ACI): a manifesto. Interactions 18(4):69-73

26. Markoff J (2011) Researchers show how a car's electronics can be taken over remotely. NYTimes.com, 9.3.2011. http://www. nytimes.com/2011/03/10/business/10hack.html

27. OECD (2012) Verkehrstote. Die OECD in Zahlen und Fakten 2011-2012: Wirtschaft, Umwelt, Gesellschaft, OECD Publishing. http://dx.doi.org/10.1787/9789264125469-57-de

28. Pieper A (2007) Einführung in die Ethik. 6. revised and updated edition. A. Francke Verlag, Tübingen, Basel

29. PresseBox (2012) "Jagdsaison" im Straßenverkehr bringt eine Million Tiere zur Strecke. PresseBox, 20.9.2007. http://www. pressebox.de/pressemitteilung/ace-auto-club-europa-ev/Jagdsai son-im-Strassenverkehr-bringt-eine-Million-Tiere-zur-Strecke/ boxid/127106

30. Stoller D (2013) Vollautomatisch und ohne Fahrer in der Stadt unterwegs. Ingenieur.de, 15.7.2013. http://www.ingenieur.de/ Themen/Automobil/Vollautomatisch-Fahrer-in-Stadt-unterwegs

31. Tellmann D (2011) Hardware-in-the-Loop-gestützte Entwicklungsplattform für Fahrerassistenzsysteme: Modelle der surround sensorics und angepasste Fahrermodelle. Dissertation. Kassel university press, Kassel

32. Vieweg C (2013) Das Auto wird autonom. AUTOMOBILProduktion 11(2013): 48

33. Wallach W, Allen C (2009) Moral machines: teaching robots right from wrong. Oxford University Press, New York

34. Wolf U (2012) Ethik der Mensch-Tier-Beziehung. Klostermann, Frankfurt/Main

35. Wollan M (2010) Mapping Traffic's Toll on Wildlife. The New York Times, 12.9.2010 